\title{
El intérprete y la fidelidad a la partitura: una perspectiva general aplicada a la Percusión
}

\author{
The Performer and Fidelity to the Sheet Music: A General Perspective \\ Applied to Percussion
}

\author{
Julio Miguel Sánchez-Andrade Fernández \\ Conservatorio Superior de Música de Asturias \\ juliosanchez_andrade@yahoo.es
}

\section{RESUMEN}

Esta es otra de las controversias más comunes en la enseñanza de la interpretación musical y, quizá también, en el arte interpretativo en general. ¿Hasta qué punto deben respetarse las indicaciones del autor? ¿Hasta dónde es obligatoria la fidelidad al texto o werktreue? ¿Dónde está el límite de una interpretación inspirada?

Palabras clave: Investigación, intérprete, percusión, pedagogía, conservatorio de música.

\begin{abstract}
The following reflexion constitutes another of the most prevalent controversies concerning the training of musical performance, and maybe the whole realm of performing arts: To what extent should we follow the indications of the author? How far can we go regarding the faithful rendition of the original text or werktreue? Which are the boundaries of an inspired performance?
\end{abstract}

Key words: Research, Performer, Percussion, Pedagogy, Conservatory of Music.

Sánchez-Andrade Fernández, J. M. (2018). El intérprete y la fidelidad a la partitura: una perspectiva general aplicada a la Percusión. Cuadernos de Investigación Musical, 4, 80-93.

doi: http://dx.doi.org/10.18239/invesmusic.v0i4.1817 


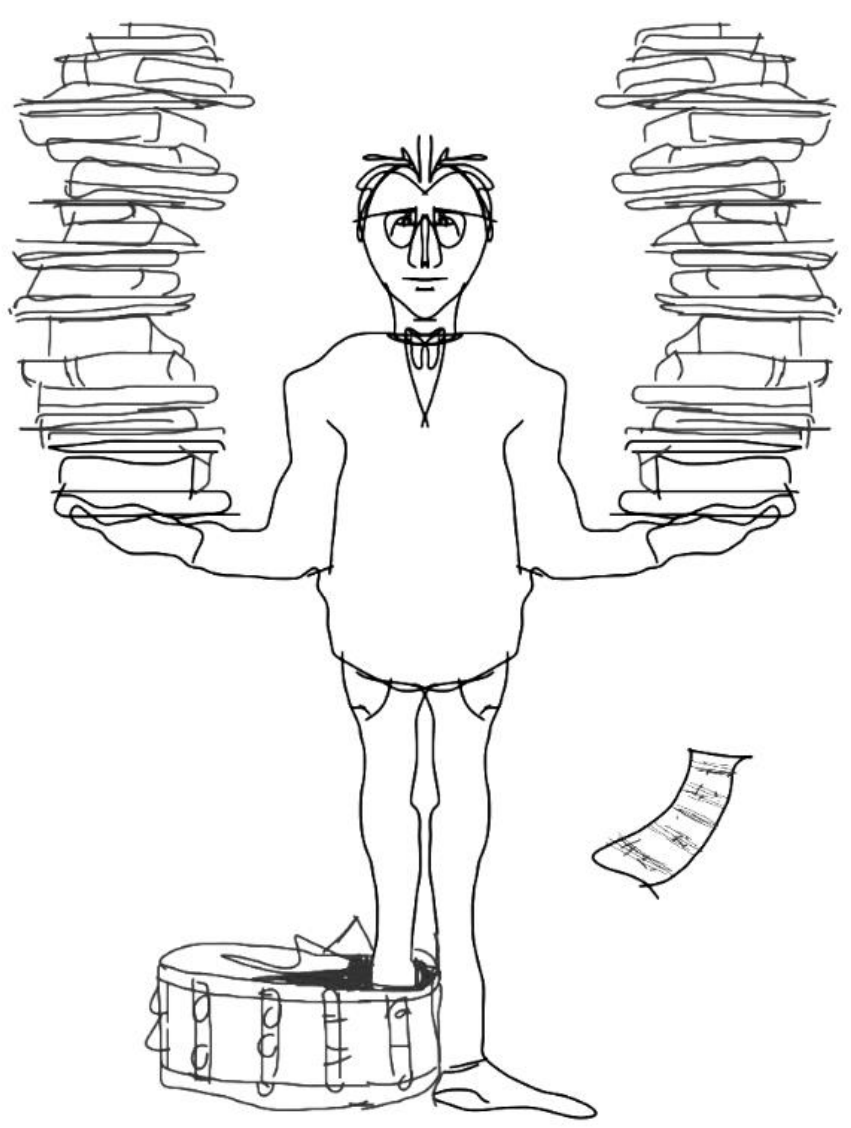

Figura 1. El precio de la fidelidad al texto.

Ilustradora: María Aranguren.

\section{ENFOQUE TEÓRICO}

El enfoque teórico, a decir de algunos especialistas, es la base de la construcción de una investigación, es decir, la definición de los problemas tratados en ella, la etapa de la investigación en la que se expresa con un mayor nivel de abstracción todo lo relacionado con ella. En asuntos como la fidelidad al texto, hay profesores que siguen al pie de la letra el famoso dicho: "toca lo que pone ahî". Sin menoscabo de la importancia que tiene respetar la obra del compositor, debemos considerar la trascendencia que comporta el criterio del intérprete y la necesidad de que una misma obra no suene exactamente igual en sus distintas interpretaciones, ya que las diferencias de criterio configuran lo que hemos denominado "personalidad interpretativa". Todas las piezas u obras admiten un cierto grado de interpretación: "Por último, tengo que hacerme también la pregunta: ¿Qué nivel de interpretación soporta en realidad esta pieza?” (Mantel, 2010: 112). 


\section{JuLIo Miguel SÁNCHEZ-ANDRADE FERNÁNDEZ}

\section{OBJETIVOS}

Nuestro objetivo principal es aclarar la relevancia de la personalidad interpretativa del estudiante, y debatir la importancia de la fidelidad a la partitura y los límites que pueden concederse a las aportaciones del intérprete. En nuestro caso, lo hacemos desde la perspectiva de un percusionista; sin embargo, hay elementos comunes a otros instrumentistas ya que se antepone el enfoque musical.

\section{DESARRollo DE LA inVESTigación}

En la enseñanza musical es muy común haber escuchado alguna vez cómo algunos profesores piden a sus estudiantes que interpreten lo que está escrito, en referencia a que las obras deben tocarse tal cual aparecen en la partitura, y que el margen interpretativo debe ser muy reducido o inexistente. Y no es extraña esta estricta y literal forma de verlo, ya que cuenta Jonathan O. Ursom (1993) que compositores como Stravinski o Ravel pensaban que el cometido de un intérprete era exclusivamente hacer sonar una partitura musical determinada; podríamos llamarlo, "trasladar el texto a la música". Pedían a los intérpretes de su música convertir la partitura en sonido, lo que implicaba hacer invisible su personalidad interpretativa de la que hablaremos más adelante:

La extendida aversión a la "interpretación" (en su acepción más subjetiva) se ha vinculado a menudo con el neoclasicismo stravinskiano, ya que los músicos rehuían no sólo el virtuosismo y el exhibicionismo, sino el intervencionismo de cualquier tipo (Lawson y Stowell, 2009: 24).

Abundando en esta paradoja -que fuera un compositor genial, creativo y moderno el que no permitiera margen creativo a sus intérpretes-, Stravinski pertenece a un siglo que creó un tipo de notación que propiciaba la improvisación y la aleatoriedad:

En 1947, Stravinsky condenó la interpretación y exigió un enfoque estrictamente objetivo por parte del intérprete. Sin embargo, la notación musical se extendió incorporando elementos gráficos no convencionales para inspirar la improvisación, mientras que los principios aleatorios (o de probabilidad) también constituían una fuente de experimentación (Lawson, 2006: 30).

La forma restrictiva de tocar, lejos de ser fiel al texto -según Gerhard Mantel-, traería consigo un planteamiento interpretativo equivocado: "La exhortación expresada con tanta frecuencia por los pedagogos, “Toca lo que pone ahí", conduciría incluso, si se sigue al pie de la letra, a un "error de lectura" (Mantel, 2010: 31). 


\section{EL INTÉRPRETE Y LA FIDELIDAD A LA PARTITURA: UNA PERSPECTIVA GENERAL APLICADA A LA PERCusión}

El mismo autor nos muestra que es preciso saber leer entre líneas para interpretar las indicaciones. La referencia buena es el sonido y no tanto el texto, ya que este es a veces un obstáculo en vez de una buena guía. En términos generales, lo que cuenta es el resultado sonoro, lo musical:

Cuando uno cree de buena fe en la notación y se esfuerza por ser fiel al texto, la ejecución de dicha indicación se exagera a menudo tanto que pierde todo sentido en el seno de la estructura de la música, de forma que sería más recomendable ignorar la indicación. La partitura puede por lo tanto en algunos casos inducir a error [...] ¡El sonido es más importante que la partitura! (Mantel, 2010: 108-109).

La partitura proporciona cierta información sobre las intenciones del compositor; sin embargo, en ocasiones se ha analizado el modo en que el intérprete manipula ciertos aspectos de la partitura (tempo, dinámicas, agógicas...) para expresarse mejor ante el público (Gabrielsson y Juslin, 1996: 68-91).

Un intérprete tan reputado como Alfred Brendel opina que debe seguirse la partitura con la mayor fidelidad. Aunque, teniendo en cuenta que no todas las intenciones del autor pueden verse reflejadas en ella, debe obrarse con una lógica musical y ser conscientes de que no hay una correspondencia exacta entre texto e interpretación:

¿Hay que tocar lo que el compositor puso por escrito? Sí, en la mayor medida posible [aunque] la confianza ciega en el texto puede resultar desmedida [...] El mensaje completo no se halla únicamente en el texto (Brendel, 2013: 52).

Según algunos pedagogos, la verosimilitud de los textos musicales utilizados en Occidente se aproxima mucho al sistema de notación ideal, lo que nos hace pensar que una partitura puede representar con fidelidad muchas de las ideas del compositor: "Sólo los sistemas más rigurosos, como los que se hallan implícitos en las matemáticas y en la notación musical utilizada en Occidente, se corresponden con el ideal de un sistema notacional completo" (Gardner, 2011: 27).

Concertistas célebres y muy experimentados -caso de Maurizio Pollini- destacan el equilibrio que debe haber entre lo que está escrito y lo que ha de ser interpretado, resaltando la idea de que la partitura debe interpretarse, de que si el músico no la personaliza ni la interioriza -lo que se entiende por "hacerla suya"-, no debería tocarla:

En la música deben conjugarse, a partes iguales, objetividad y subjetividad; racionalidad e irracionalidad tienen que convivir. El compositor ha escrito algo de una determinada manera, pero yo debo filtrar eso a través de mi propia sensibilidad. Si no siento algo, si no lo hago mío en cierto sentido, no puedo tocarlo (Pollini, 2014). 


\section{JuLIo Miguel SÁNCHEZ-ANDRADE FERNÁNDEZ}

Utilizando la lógica musical, puede seguirse un texto con fidelidad, sin olvidar que se trata de una expresión artística, con una lógica de interpretación que no puede someterse férreamente a unas normas escritas:

Cuando un compositor escribe piano al inicio de un pasaje, no deroga por ello las reglas de la percepción humana basadas en una dinámica cambiante. El compositor define con ello más bien un marco [...] Malentendidos parecidos aparecen igualmente en el ámbito del tempo. Algunos músicos opinan a conciencia que la "fidelidad al texto" significa mantener estrictamente durante una pieza completa la cifra metronómica prescrita por el compositor (Mantel, 2010: 159).

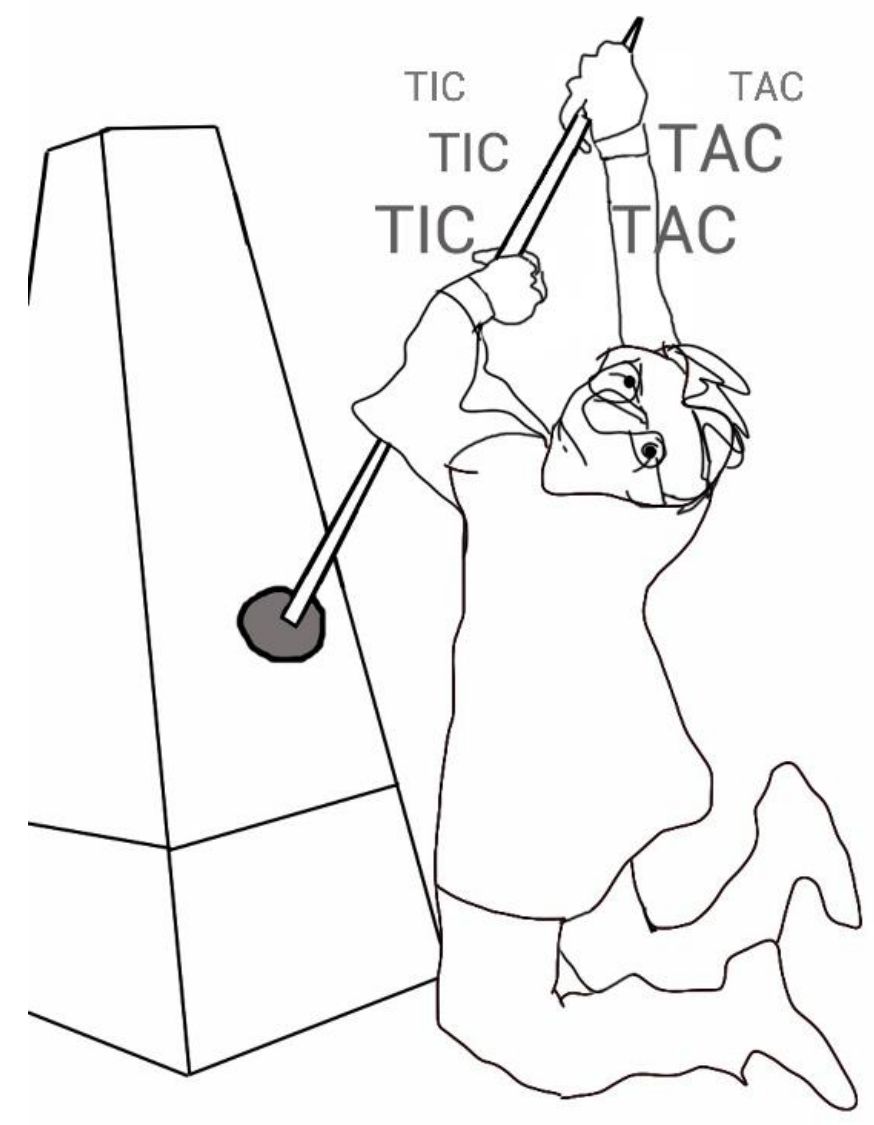

Figura 2. La esclavitud del tempo.

Ilustradora: María Aranguren.

La propia condición de una partitura hace que las intenciones del autor no puedan anotarse con total precisión y recaiga en el intérprete la obligación y oportunidad de interpretarla: él, por el hecho de tocarla, asume una serie de responsabilidades que debe afrontar con sus conocimientos técnico, musical y estilístico, tomando decisiones que van más allá de lo textual: 


\section{EL INTÉRPRETE Y LA FIDELIDAD A LA PARTITURA: UNA PERSPECTIVA GENERAL APLICADA A LA PERCusión}

La partitura misma es un mecanismo impreciso, que por su propia naturaleza ofrece aún al intérprete más consciente de sus deberes una rica variedad de posibilidades. Siempre ha habido un gran número de detalles que un compositor no se preocupó de escribir en sus partituras; sabía simplemente que se observarían ciertas convenciones. Algunas de ellas han dejado de estar en vigor, mientras que otras han experimentado importantes cambios de significado (Lawson y Stowell, 2009: 16).

En lo referente a la notación, no parece oportuna la comparación de la música con otras artes como la literatura, escultura, pintura, arquitectura, etcétera, porque estas son obras acabadas en su formato gráfico, son un producto final en sí mismas y se entienden sin intérprete; sin embargo, desde nuestra perspectiva, sí podríamos equiparar las partituras con los textos de teatro o los guiones de cine -auténticos "marcos" de las intenciones del autor, que deben ser interpretadas-, que, como la música, necesitan de un mediador para llegar a hacerse realidad, a cobrar todo su sentido. En el texto solo contamos con parte del mensaje; cierto que, dependiendo de un arte u otro, con distinto grado de concreción. El resto debe aportarlo un intérprete: así llegaremos al interior de la obra.

En primer lugar, tendríamos que determinar qué significa "interpretación” y qué es "apropiarse" de un texto. De las dos formas de tocar que se expresarán, la primera parece la más adecuada si queremos respetar la idea del autor:

[...] podríamos llamar "interpretación" al primer tipo de ejecución "vinculando el término a su significado esencial" y "apropiación" al segundo tipo (ya que, en cierto sentido, la obra musical se convierte en un medio que el intérprete utiliza para su objetivo personal). La interpretación, por lo tanto, puede ser sinónimo de intentar determinar y realizar las intenciones del compositor" (Walls, 2006: 36).

Nuestro planteamiento es que, a partir de un texto determinado, que debe tratarse con respeto ya que constituye la expresión de las ideas e intenciones del autor, surge la posibilidad de interpretar. De cualquier manera, huimos de las declaraciones radicales e intransigentes en el sentido de no tomarse ninguna licencia, de tratar de tocar exactamente lo escrito, del famoso "toca lo que pone ahí". Resultaría imposible, y eso nos induciría a cometer aún más errores que aplicando una excesiva libertad:

La aspiración por alcanzar la completa corrección textual desemboca inevitablemente - por causa de su imposibilidad- en la arbitrariedad, pues en cada uno de los parámetros descritos se escurrirían pequeñas desviaciones incontrolables que impedirían incluso que pudiese reproducirse el texto propiamente dicho (Mantel, 2010: 157-158). 


\section{Julio Miguel SÁNCHEZ-ANDRADE FERNÁNDEZ}

Parece que concertistas tan admirados por su mesura y virtuosismo como Arthur Rubinstein, aconsejaban: "Toca primero exactamente lo que está escrito. Si le has hecho plena justicia y aun así le quieres añadir o cambiar algo, pues hazlo” (Ritterman, 2006:105).

Cuando tratamos obras cuyo compositor es, además, intérprete de ellas -lo que en Percusión suele ser bastante habitual -Fink, Rosauro, Stout, Abe, Burton, Kopetzki, Zivcovic, Masson, Gerassimez, Tasca, Sammut, Leonard, Schmitt, Séjourné, Cangelosi, Sammut, Gathreaux, Regolí o Goyeneche, entre muchos otros-, nos encontramos con una cierta libertad de interpretación, que varía dependiendo del momento: "También el propio compositor, en tanto que intérprete, ejecuta y ha ejecutado sus obras de manera diferente de mañana” (Mantel, 2010: 28).

La tarea comunicadora de un músico implica expresividad, lo cual le lleva a trascender el texto: “[...] se espera que los músicos den vida a la música, que vayan más allá de lo que proporciona explícitamente la notación o la transmisión oral -que sean “expresivos"- (Clarke, 2006: 82).

Aún hay más argumentos para defender la necesidad de ir más allá de la partitura. A pesar de las citadas teorías de algunos pedagogos al respecto de la verosimilitud de los textos musicales utilizados en Occidente, una de las razones para trascender el texto sería la incapacidad del sistema de notación utilizado para determinar todos los detalles, para precisar las intenciones del autor. De ahí que sea tan necesaria la interdisciplinariedad para entender la obra y que cada interpretación sea felizmente distinta:

El punto de partida de una interpretación de música occidental suele ser una partitura, que consiste en una serie de instrucciones con diversos grados de imprecisión que el intérprete debe traducir en sonidos. La imprecisión inherente a la notación musical occidental implica que la decodificación de la partitura requiere un considerable aporte y conocimiento por parte del intérprete. Por consiguiente, cada interpretación de una obra es diferente (Reid, 2006: 125).

Algo parecido a lo que argumentaba el director historicista Nikolaus Harnoncourt: "La notación es, por tanto, un sistema extremadamente complejo de escritura codificada [...] Para cada músico, sin embargo, debería estar claro que esa notación es muy inexacta, que precisamente las cosas que nos dice no nos las indica con precisión" (Harnoncourt, 2006: 37-38).

Como un hecho común, constatado en otros ámbitos de la comunicación, tratar de transmitir algo con total fidelidad y certeza puede obrar negativamente y deteriorar el contenido estético:

En la medida en que un sistema de símbolos (como el lenguaje) se utiliza para comunicar un único significado de una manera tan inequívoca como sea posible, con una alta posibilidad y traducción y resumen exactos, no funciona estéticamente (Gardner, 2011: 30) 


\section{EL INTÉRPRETE Y LA FIDELIDAD A LA PARTITURA: UNA PERSPECTIVA GENERAL APLICADA A LA PERCusión}

Otro de los factores que deben tenerse en cuenta para guardar mayor o menor lealtad a la partitura son las intenciones del compositor con sus anotaciones; teniendo en cuenta el diferente grado de literalidad que pretenda: "La regla moderna según la cual debemos tocar únicamente lo que está escrito en la partitura no viene al caso cuando la notación del compositor no pretendía ser restrictiva" (Johnson, 2006: 235). Ocurre de modo parecido cuando el compositor delega en el intérprete o se le conduce de modo incierto: "La indeterminación surge cuando al intérprete se le requiere elegir el orden del material o se le guía mediante algún proceso hacia un orden evidentemente aleatorio o fortuito" (Lawson, 2006: 31). También es preciso considerar la precisión y minuciosidad de los compositores: "[...] los mismos signos pueden significar algo diferente dependiendo del compositor. No todo el mundo anotó lo esencial con tanto sentido como Beethoven" (Brendel, 2013: 120121).

Sin embargo, actualmente y por parte de algunos autores, la partitura ha llegado a considerarse como el punto de referencia indudable e intocable, el sentido final de la obra, juzgando la labor del intérprete como una imagen inexacta de la composición. Son criterios interpretativos que no se ajustan a otros tiempos no menos florecientes en lo musical, en los que "gran parte del material musical estaba esbozado más que escrito en toda su extensión" y en los que "los instrumentistas y cantantes seguían aportando una parte importante":

La abrumadora supremacía actual de la partitura, que exige fidelidad y exactitud a toda costa, no es de ningún modo característica de la historia de la interpretación en su conjunto. Sin embargo, la literatura musical suele dar la impresión de que el verdadero significado estético reside en la notación, y que la interpretación es, como mucho, una representación imperfecta y aproximada de la obra misma (Lawson, 2006: 20).

El margen interpretativo que nosotros consideramos dependerá igualmente del tipo de música que se esté tocando, ya que no será el mismo en todos: en las transcripciones para percusión de música barroca hay un gran margen de interpretación, lo que puede observarse en la diversidad de versiones grabadas disponibles -originales o adaptadas para marimba- de cualquiera de las suites para cello de Bach, por ejemplo. Ebenezer Prout, en el Grove's Dictionary, sostiene que "la interpretación literal de la música de Bach y Haendel no refleja las intenciones del compositor” (Lawson, 2006: 29). La notación anterior a 1800 muestra la obra en sí, pero no especifica cómo debe tocarse -son meras indicaciones-, por eso debe enseñarse a leerla y tratarla de modo diferente a la notación posterior: "cómo hay que leerla, qué significaban esas notas para el músico de entonces” (Harnoncourt, 2006: 3941). "[Ya que] el compositor sólo escribía las partes externas, el resto era cosa de los intérpretes [...] La obra y la ejecución permanecían por tanto claramente separadas" (Harnoncourt, 2006: 56-57). Aunque entonces se editaran partituras con mayor exactitud 


\section{JuLIo Miguel SÁNCHEZ-ANDRADE FERNÁNDEZ}

que otras, las mejores no eran más que una referencia: "Incluso los textos fiables sólo ofrecen una idea parcial de lo que se interpretaba originalmente, ya que los instrumentistas y cantantes seguían aportando una parte importante" (Lawson, 2006: 26). En algunas cantatas de Bach, aparece determinado por el propio autor más de una manera de articular un fragmento, lo que quiere decir que, habiendo articulaciones inadecuadas, es posible articular bien de distintas maneras -incluso dos voces simultáneas de forma diferente- y el intérprete debe decidir el modo: "[...] Bach está diciendo: no existe sólo una articulación correcta para una figura musical, sino varias; aquí incluso ¡simultáneamente!” (Harnoncourt, 2006: 67).

En épocas más modernas, en la música original para percusión de la segunda mitad del siglo Xx y los inicios de este XXI, la tolerancia en cuanto la aportación personal -aunque dependiendo de autores e instrumentos- es bastante amplia. Y si nos referimos al campo del jazz -enseñanza que nosotros preconizamos incluir en la educación generalista de un conservatorio superior- no se plantea esa falta de fidelidad al texto, porque lo más importante no es el tema, sino la forma de interpretarlo; la capacidad para improvisar y crear una pieza nueva en cada interpretación:

[...] en el jazz tradicional [...] tiene poco sentido considerar si un intérprete es más o menos fiel al original [...] Un "clásico" [en el campo del jazz] tiene una identidad que frecuentemente no es mucho más que una estructura armónica/métrica y una melodía, y representa una base sobre la cual se espera que los intérpretes exhiban sus habilidades improvisatorias [...] Los oyentes de jazz están más interesados en la interpretación y los intérpretes que en las piezas y repertorios (Clarke, 2006: 222).

Sin embargo, en el repertorio orquestal sinfónico para percusión "tutti" apenas hay margen interpretativo y, en todo caso, se reduce a seleccionar el tamaño, material o tipo del instrumento -cuando tratamos con accesorios como triángulos, panderetas, castañuelas, platos, etcétera-; si nos referimos a otros instrumentos, decidir el tipo de baqueta -de mayor o menor dureza, longitud, peso, etcétera-, buscar una leve adecuación de la dinámica para empastar con el resto de la orquesta, una determinada sonoridad con un diferente tipo de ataque, o elegir el lugar y ángulo de impacto, pero no en aspectos interpretativos como tales, ya que estos corresponden casi exclusivamente al criterio del director de la orquesta.

Esta investigación se basa en la metodología cualitativa -aunque solo en parte, ya que también se han considerado las opiniones de diversos pedagogos musicales y las experiencias de aula propias del autor de este artículo-, producto del trabajo de campo obtenido en más de una docena de entrevistas personales realizadas a profesores de Percusión con destino en conservatorios superiores de música españoles. Resumiremos sus opiniones, transcribiendo -para no pecar de exhaustivos- solo algunos de sus comentarios respecto a la interpretación del repertorio orquestal. Cuando nos referimos a la interpretación de partituras de los siglos Xx y XXI, en las que el percusionista actúa como solista, la valoración cualitativa de las opiniones de los profesores consultados es muy diversa: aquellos que enseñan a tratar las partituras al pie de la letra sin permitir ninguna 


\section{EL INTÉRPRETE Y LA FIDELIDAD A LA PARTITURA: UNA PERSPECTIVA GENERAL APLICADA A LA PERCuSIÓN}

personalización, y los que contemplan un margen creativo del intérprete bastante amplio. En todo caso, está patente el consenso de que el texto debe ser respetado y que no debe adulterarse el mensaje de su autor. Asimismo, cuando se refieren a la interpretación del repertorio orquestal, también hay acuerdo en el poco margen interpretativo:

Tu papel decisorio a la hora de decidir ciertas cosas, es bastante limitado [...] la interpretación del conjunto, que es una orquesta, está decidida mucho por el director [...] En comparación a cuando tocas una obra solo, o una obra de cámara, o puedas crear tu propia obra $[\ldots]$ el porcentaje creativo, ¿no? Es muy mínimo [...] sí que tienes un pequeño margen que puedes elegir un timbre [...] o un efecto, o... (M. Ramada, comunicación personal, 18 julio, 2014).

El trabajo orquestal... Creativo, interpretativo... Es de lo que menos margen tiene de creatividad [...] hay otro tipo de trabajos que pueden dar más lugar a la libre interpretación [...] Pero el trabajo de orquesta, lamentablemente, está poco evolucionado a mi juicio [...] Está todo como muy clarito, y no tiene mucho margen de creatividad (R. Giovanetti, comunicación personal, 23 julio, 2014).

¿Hasta qué punto puedes ser creativo? La verdad es que no hay mucho margen [...] te puede llevar a algunos criterios de elección de panderetas, de triángulos, los platos que quieres utilizar... [...] Elección de instrumentos, baquetas... (M. A. Orero, comunicación personal, 28 julio, 2014).

Un músico en orquesta no interpreta. Pide cómo se debe interpretar el director. Lo que pasa que, a veces, eso en una percusión, no es tan claro. [...] los buenos directores delegan en los buenos solistas (J. Cerveró, comunicación personal, 29 julio, 2014).

No, no puede ser. El maestro es quien manda. Bueno, uno siempre puede imprimir su personalidad o su sonido (P. García Ríos, comunicación personal, 9 junio, 2015).

En este sentido, añadiremos que Anthony J. Cirone (2008: 11) comenta su concienzudo y fundamentado estudio del contexto musical para saber el tipo de platillo que Dvorak habría preferido en tres compases del $4^{\circ}$ movimiento de su Sinfonía del Nuevo Mundo. Tras llegar a la conclusión de que sería un platillo suspendido, a la manera que Berlioz había puesto de moda más de sesenta años antes en su Sinfonía fantástica, tuvo que ceder ante los requerimientos sonoros del director Herbert Blomsted, quien, en vez de un platillo suspendido, quería oír dos platos chocados al estilo "swish" (resbalando el borde de un platillo sobre el interior del otro), dando al traste con la puesta en práctica de tan meticulosa averiguación. Esta anécdota da idea de las pocas opciones -ya no 


\section{JuLIo Miguel SÁNCHEZ-ANDRADE FERNÁNDEZ}

interpretativas, sino incluso para elegir el instrumento adecuado o el modo de obtener su sonido- que tiene un percusionista orquestal.

Tratando la interpretación del texto en términos generales -sin limitarlo al campo "tutti" orquestal-, es muy significativo el comentario de Richard Taruskin, quien sostenía que "la necesidad de satisfacer las intenciones de un compositor (suponiendo que ello fuera posible) demuestra una falta de valentía, por no decir una dependencia infantil" (Taruskin, 1995: 98). Asimismo, el semiólogo musical Jean Jacques Nattiez defiende la subjetividad para interpretar la partitura: "[...] el ejecutante tiene todo el derecho a la libertad de interpretación, incluso a tener más de una concepción de una misma obra" (Nattiez, 1993: 46-47).

Interesa, de todos modos, actuar con equilibrio y mesura, conocer la obra, su estructura y contexto; ser respetuoso y consciente del margen para personalizar la interpretación:

Existen límites, claro está, en cuanto a los "alejamientos" esperados o permitidos convencionalmente. En la tradición concertística occidental, no se espera que el intérprete cambie las notas y ritmos de una pieza de música o que cambie el orden de los movimientos o secciones [...] Pero incluso dentro de esos límites, los intérpretes tienen muchísimas posibilidades de adoptar enfoques diferentes (Clarke, 2006: 85-86).

El genio y creatividad de un intérprete le harán ser renuente con las normas y mostrar su subjetividad; sin embargo, deberá adquirir la capacidad de ser equilibrado y transitar por ese difícil y estrecho margen en el que texto y proceso interpretativo deben convivir:

Los intérpretes han de recorrer el difícil camino entre la necesidad de respetar la partitura, que representa las intenciones del compositor, y el deseo de poner en práctica su propia perspicacia creativa $[. .$.$] interpretar música es un proceso muy subjetivo y resistente a$ las recomendaciones normativas (Reid, 2006: 130).

Aunque en este caso se trate de música antigua, los intérpretes más reconocidos defienden su personalidad interpretativa, aún pensando - sin que exista contradicción- que su propósito es ser fieles a las intenciones del autor:

La clavecinista Wanda Landowska, la primera "personalidad" de la música antigua, consideraba la idea de objetividad como algo utópico, ya que ningún intérprete debería limitarse a permanecer a la sombra del autor. $\mathrm{Al}$ mismo tiempo pudo afirmar que aspiraba a servir únicamente a sus compositores (Lawson y Stowell, 2009: 24). 


\section{EL INTÉRPRETE Y LA FIDELIDAD A LA PARTITURA: UNA PERSPECTIVA GENERAL APLICADA A LA Percusión}

Así pues, la diferencia de criterios y de puntos de vista para juzgar la mayor o menor libertad de interpretación es una constante entre los distintos intérpretes y profesores:

[...] lo que a uno le resulta díscolo y caprichoso (basándose quizá en que "se aleja de la partitura") a otro le puede parecer comprometido e inspirado (por la "originalidad e idiosincrasia de su interpretación”) (Clarke, 2006: 222).

Deberíamos considerar los comentarios de pedagogos e intérpretes de tanto prestigio como Rink o Mantel al respecto de la fidelidad y tratamiento de los textos. El primero de ellos dice que: "la partitura no es 'la música' y que, aunque uno quiera, nunca se puede ser totalmente fiel a ella" (Rink, 2006: 14). El segundo concluye, a modo de resumen, que debe respetarse la partitura, pero también la música mediante el entendimiento de la obra, y se refiere a la honestidad que todo intérprete debe tener: "Así, partiendo de la fidelidad al texto, y a través de su comprensión, llegaremos a la fidelidad a la música, a nuestra interpretación” (Mantel, 2010: 137).

Como colofón, surge la siguiente pregunta: ¿Puede un compositor esperar tener alguna influencia en cómo se interpreta su música después de haberla escrito, y qué obligación moral hay de satisfacer sus intenciones originales? (Lawson y Stowell, 2009: 30).

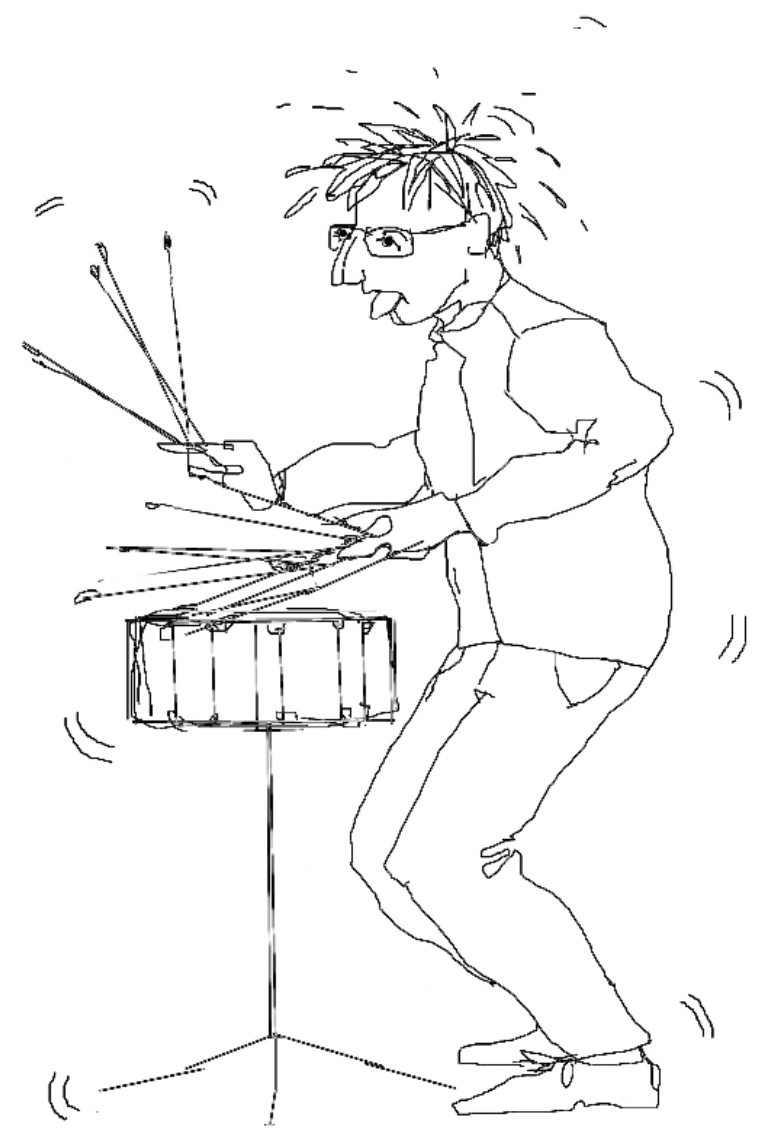

Figura 3. Persiguiendo al autor.

Ilustradora: María Aranguren. 


\section{JuLIo Miguel SÁNCHEZ-ANDRADE FERNÁNDEZ}

\section{CONCLUSIONES Y LÍNEAS EDUCATIVAS PROPUESTAS}

En cuanto a la fidelidad debida al texto, concluimos que, teniendo en cuenta acreditadas opiniones que aseguran que "la partitura no es 'la música' y que, aunque uno quiera, nunca se puede ser totalmente fiel a ella" (Rink, 2006: 14), es posible respetar las intenciones del autor mediante una profunda comprensión de la obra y, a partir de ahí, considerando los márgenes admisibles, conseguir una interpretación personal. En nuestra experiencia docente hemos comprobado que aún es bastante común enseñar exigiendo absoluta literalidad.

Los márgenes del respeto a la literalidad textual. Teniendo en cuenta que "la ejecución cabal no siempre se corresponde con la notación” (Brendel, 2013: 93), y que no es propio de una enseñanza musical innovadora restringir al estudiante con la exhortación "toca lo que pone ahí", nuestra sugerencia y línea educativa propuesta es realizar un reflexivo estudio de la obra para conocer qué es imprescindible respetar y qué es más accesorio, y a partir de ahí contextualizando la pieza y sabiendo el margen interpretativo permisible en cada casoaportar nuestra propia visión de ella, trascendiendo el texto sin dejar de ser fiel a él.

\section{BIBLIOGRAFÍA}

Brendel, A. (2013). De la A la $Z$ de un pianista. Un libro para amantes del piano. Barcelona: Acantilado.

Cirone, A. J. (2008). On Musical Interpretation in Percussion Performance. A Study of Notation and Musicianship. Galesville, MD: Meredith Music.

Clarke, E. (2006). “Comprender la psicología de la interpretación”. En John Rink (ed.). La interpretación musical, pp. 81-94. Madrid: Alianza Música.

Gabrielsson, A. y Juslin, P.N. (1996). "Emotional expression in music performance: Between performer's intention and listener's experience". Psychology of music, 24, pp. 68-91.

Gardner, H. (2011). Educación artística y desarrollo bumano. Barcelona: Ed. Paidós.

Harnoncourt, N. (2006). La música como discurso sonoro. Hacia una nueva comprensión de la música. Barcelona: Acantilado.

Johnson, P. (2006). "El legado de las grabaciones". En J. Rink (ed.). La interpretación musical, pp. 232-247. Madrid: Alianza Música. 
EL INTÉRPRETE Y LA FIDELIDAD A LA PARTITURA: UNA PERSPECTIVA GENERAL APLICADA A LA PERCUSIÓN

Lawson, C. (2006). "La interpretación a través de la historia". En John Rink (ed.). La interpretación musical, pp. 19-34. Madrid: Alianza Música.

Lawson, C. y Stowell, R. (2009). La interpretación histórica de la música (tr. Luis Carlos Gago Bádenas). Madrid: Ed. Alianza Música

Mantel, G. (2010). Interpretación. Del texto al sonido. Madrid: Alianza Música.

Nattiez, J. J. (1993). “Gould Hors-Temps”. Dans Le Combat de Chronos et d'Orphée: essais. Paris: Bourgois.

Pollini, M. (15 de noviembre de 2014). "En la música tienen que convivir racionalidad e irracionalidad". La Voz de Galicia.

Reid, S. (2006). "Preparándose para interpretar". En John Rink (ed.). La interpretación musical, pp. 124-136. Madrid: Alianza Música.

Rink, J. (2006). “Análisis y (¿o?) interpretación”. En John Rink (ed.). La interpretación musical, pp. 55-80. Madrid: Alianza Música.

Ritterman, J. (2006). “Sobre la enseñanza de la interpretación”. En John Rink (ed.). La interpretación musical, pp. 98-110. Madrid: Alianza Música.

Taruskin, R. (1995). Tex and Act: Essays on Music and Performance. Nueva York y Oxford: Oxford University Press.

Ursom, J. O. (1993). “The ethics of musical performance”. In M. Krausz (ed.), The Interpretation of Music: Philosophical Essays, pp. 157-164. Oxford: Oxford University Press.

Walls, P. (2006). "La interpretación histórica y el intérprete moderno”. En John Rink (ed.). La interpretación musical, pp. 35-54. Madrid: Alianza Música.

Fecha de recepción: 23/01/2018

Fecha de aceptación: 17/05/2018 